\title{
Recurrence rates and long-term survival factors in young women with breast cancer
}

\author{
Hassan K. Abdulwassi, MBBS, Ibrahim T. Amer, MBBS, Ahmad H. Albibshi, MBBS, Abdullah A. Alnajjar, MBBS, \\ Abdulrahman K. Bahatheq, MBBS, Nora H. Trabulsi, MD, MSc, Mohammed O. Nassif, MD, FRCS.
}

\begin{abstract}
الأهداف : نهدف في هذه الدراسة لمعرفة العوامل المؤثرة على عودة الورم

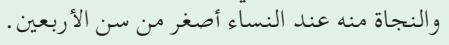

الطريقة : تم مراجعة سجلات المرضى بجامعة الملك عبد العزيز البالغين أربعين

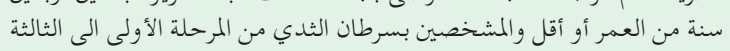

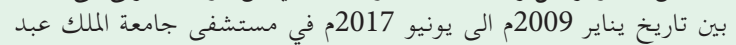

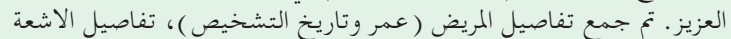

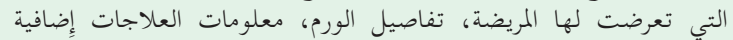

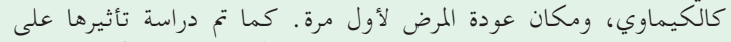


(DFS)، and overall survival (OS



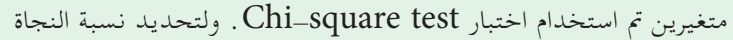

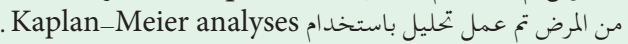

النتائج : تم ادراج 117 مريضة في التحليل الاحصائي . الوسيط للمتابعة قدر 0 لبور



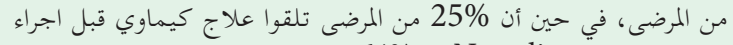



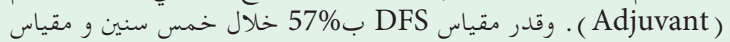

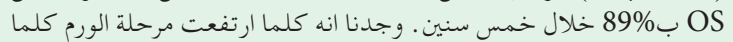
أثرت على معامل نجاه DFS أسوأ ( 89 (



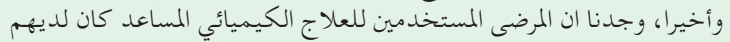

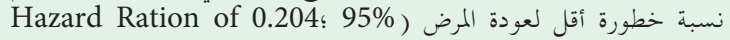
. ( confidence interval، $0.050-0.832$ ؛ $=0.027$

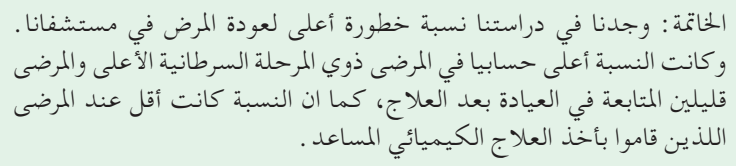

Objectives: To evaluate the factors related to breast cancer (BC) recurrence as well as survival in women $\leq 40$ years old.

Methods: This is a retrospective medical record review of women aged $\leq 40$ years diagnosed with BC stages I to III between January 2009 and June 2017 at King Abdulaziz University Hospital (KAUH), Jeddah, Saudi Arabia. Demographic data collected included patients' initial presentation (including age and date of diagnosis), imaging studies, tumor characteristics, type of surgery, systemic therapy (if any) received, and site of first recurrence. Data was analyzed to assess recurrence rate, disease-free survival (DFS), and overall survival (OS), and determine associated factors. Descriptive statistics were used to calculate the mean, median, standard deviation, and quartiles. Chi-square test was performed to test the association between 2 variables. Kaplan-Meier analyses were performed to assess survival distribution.

Results: A total of 117 patients were included for analysis. Median follow-up was 16 months (range 0 to 99). Five-year DFS 57\% and OS was $89 \%$. Adjuvant chemotherapy was associated with a better DFS (hazard ratio of $0.204 ; 95 \%$ confidence interval, 0.050 to $0.832 ; p=0.027)$. Higher tumor, node, metastasis stage was significantly associated with worse DFS ( $p=0.034)$. Fewer postoperative follow-up visits significantly predicted recurrence $(p=0.003)$.

Conclusion: We found a high risk of BC recurrence among patients at our institution. Higher cancer stage, nonuse adjuvant chemotherapy, and low follow-up rate were significant predictive factors for recurrence.

Keywords: breast cancer, recurrence, survival, young women, Saudi Arabia

Saudi Med J 2020; Vol. 41 (4): 393-399 doi: 10.15537/smj.2020.4.24987

From the Faculty of Medicine (Abdulwassi, Amer, Alhibshi, Alnajjar, Bahatheq) King Abdulaziz University, and from the Department of Surgery (Trabulsi, Sassif), Faculty of Medicine, King Abdulaziz University, Jeddah, Kingdom of Saudi Arabia.

Received 9th September 2019. Accepted 3rd February 2020.

Address correspondence andreprintrequest to: Dr. Hassan K. Abdulwassi, Faculty of Medicine, King Abdulaziz University, Jeddah, Kingdom of Saudi Arabia. E-mail: Hassan_khaled_95@hotmail.com ORCHID ID: https://orcid.org/0000-0002-8295-2034 
$\mathrm{D}$ espite the fact that breast cancer (BC) is the most common cancer in women worldwide, a recent study in Saudi Arabia demonstrated very low rates of BC screening among all age groups. ${ }^{1,2}$ The study conducted a nationwide free-of-charge survey, which had a turnout of a mere 10,000 participants, and attributed the low rates of $\mathrm{BC}$ screening to the absence of a national screening program and difficult access to healthcare. ${ }^{3}$ While predominance of $\mathrm{BC}$ still lies within older age groups, younger age groups are seldom diagnosed early and unfortunately face dire prognoses with a higher recurrence rate and a diminished lifespan. ${ }^{4-6}$ Women younger than 40 years had a rate of stage IV BC that ranged from $4 \%$ to $6 \%$ in literature, while a study in India has reported a rate of $22 \% .^{7-9}$ According to the 2015 Saudi Cancer Registry report, BC was the most common newly diagnosed cancer between women in that year, accounting for 1979 (30.1\%) of all cancers. Among all the women with BC, 355 (17.9\%) patients were less than 40 years old. ${ }^{10}$ Even though surgical intervention may eradicate cancer initially and help in prolonging life expectancy, a risk high of locoregional recurrence is still there, and if not addressed properly, can be fatal. ${ }^{11}$ The Group of Early Breast Cancer Trialists' Collaborative ${ }^{12}$ and Bartelink et $\mathrm{al}^{13}$ showed a reduced mortality rate, especially for 40 years old or younger patients, whose rate of local recurrence was $19.5 \%$ with standard treatment and $10.2 \%$ with the addition of radiation therapy. Unfortunately, they did not study the factors behind the high recurrence rate. Additionally, a comparative study by Cossetti et al ${ }^{14}$ revealed that in comparing $\mathrm{BC}$ patients treated from 1986 to 1992 to patients treated from 2004 and 2008, recurrence-free survival significantly improved in all BC subtypes due to advancements in treatment and overall patient healthcare.

A study by Bijker et $\mathrm{al}^{15}$ and a meta-analysis in 2017 by $\mathrm{He}$ and $\mathrm{Zou},{ }^{16}$ concluded that age is an independent risk factor for $\mathrm{BC}$ recurrence, and concluded that younger patients have a recurrence rate of a higher risk. Other study focused on surgical treatment modalities as a risk factor for locoregional recurrence and found that this association was insignificant if the surgical margins were negative. ${ }^{17}$ Moreover, a 13 -year trend analysis revealed that patient beliefs are biased towards mastectomy as the surgical modality of choice due to

Disclosure. Authors have no conflict of interests, and the work was not supported or funded by any drug company. fear of recurrence despite the overwhelming evidence to the insignificance of that preference. ${ }^{18,19}$

Other factors play major roles in affecting the prognosis of the younger age groups and are unfortunately only found in a scarce number of studies published worldwide, such as a 2016 study by Plichta et al. ${ }^{20}$ These studies discuss the extent of BC pathological grading and staging before treatment, receptor status involved in BC cells, application of adjuvant systemic therapies and their types, long-term survival rates, and other factors.

Not understanding the risk factors for recurrence and survival will delay the detection of $\mathrm{BC}$ recurrence leading to high recurrence rates and a diminished survival rate; which, creates a psychological burden to the patient as well as an economic burden on the health care system. Therefore, this study aim to better understand these risk factors in a group of young patients by analyzing recurrence and survival patterns of women at a major university hospital and cancer referral center King Abdulaziz University Hospital (KAUH), Jeddah, Saudi Arabia.

Methods. Approval for this study was granted by the Research Committee of the Unit of Biomedical Ethics of KAUH. All patients consented to the use of their clinical data for study purposes. A retrospective review of the medical records with inclusion criteria of all women who were 40 years of age and younger diagnosed with biopsy proven BC stages I to III between January 2009 and June 2017 at KAUH was conducted. Demographic data collected included patients' initial presentation (including age and date of diagnosis), imaging studies, tumor characteristics, type of surgery, systemic therapy (if any) received, and site of first recurrence. Recurrence (either locoregional or distant), disease-free survival (DFS), and overall survival (OS) were assessed. Disease-free survival was measured from the date of the procedure until the date of recurrence and OS has been determined from the date of the procedure to the date of death or last follow-up. Breast cancer gene status was not assessed for any of the patients in our institute.

The tumor, node, metastasis (TNM) pathological staging system was used, which included all the data from the clinical staging, plus pathological evaluation (gross and microscopic) of the main cancer, regional lymph nodes and metastatic (if applicable) locations. Pathologic staging was performed according to the American Joint Committee on Cancer $^{21}$ for cancer staging, we found that the primary tumor needs to be excised without a macroscopic tumor in any resection 
margin for full pathological evaluation, and evaluation of axillary nodes includes surgical excision with sentinel lymph node biopsy evaluation in patients with stage I and stage II tumors for any nodes that are clinically negative to ensure accurate staging. Any recurrence in the ipsilateral breast, chest wall or regional lymph nodes (ipsilateral axillary, internal mammary, infraclavicular or supraclavicular) was defined as locoregional recurrence described by the American Joint Cancer Committee (AJCC 7th Edition). ${ }^{21}$ To assess the death date for each death patient, survival data were gathered from the KAUH death certificate data.

The analyses of the present study were performed using SPSS (IBM Corp, Armonk, NY, USA) version 20.0. Continuous variables were described using means, medians, standard deviations, and quartiles. The Chi-square analysis was used to evaluate categorical variables. Furthermore, we used Cox regression test for univariate analysis. The statistical significance of $p<0.05$ has been set. A non-parametric median test to assess significant differences between 2 groups was applied. Analysis of Kaplan-Meier was used to calculate the survival distribution. Furthermore, the survival distribution of 2 or more groups of a between-subjects factor was analyzed to compare for equality.

Results. Out of 1304 patients diagnosed with BC between January 2009 and June 2017, a total of 153 (11.7\%) women age 40 years or younger with biopsy proven $\mathrm{BC}$ histology were identified. Thirty-six patients (23.5\%) with stage IV disease were excluded, resulting in a study total of 117 (9\%) participants (Table 1).

At time of diagnosis, the mean age was $34.6 \pm 4$.4 years (range 20 to 40 ) with $55 \%$ being 35 years old or less. The median follow-up period was 16 months (range 0 to 99). Overall, non-Saudi patients constituted $61.5 \%$. Approximately $94.9 \%$ of patients had invasive ductal carcinoma and $58.1 \%$ had molecular subtype luminal-A. With regard to staging, $81.2 \%$ were TNM stage I or II. Lumpectomy as surgical treatment was performed to $51.3 \%$, mastectomy to $48.7 \%$, and axillary lymph node dissection (ALND) was performed at $65 \%$ of the entire population. Approximately $64.1 \%$ of patients received adjuvant chemotherapy, while no systemic therapy was received by $13.7 \%$ (chemotherapy, immunotherapy, or endocrine therapy [Table 2]). The regimens used in $75(64.1 \%)$ patients who received adjuvant chemotherapy mostly included Taxotere and Cyclophosphamide, which were used in 49 (65.3\%) patients, while other regimens included Doxorubicin and Cyclophosphamide in $16(21.3 \%)$ patients;
Table 1 - Breast cancer patient numbers and distribution by clinical stage.

\begin{tabular}{lr}
\hline Variables & $\mathbf{n}(\%)$ \\
\hline All BC patients & $1304(100)$ \\
BC patients aged 40 or younger & $153(11.7)$ \\
BC patients aged 40 or younger stages I-III (our cohort) & $117(9.0)$ \\
BC patients aged 40 or younger by stage & \\
Stage I & $31(20.3)$ \\
Stage II & $64(41.8)$ \\
Stage III & $22(14.4)$ \\
Stage IV & $36(23.5)$ \\
\hline \multicolumn{2}{c}{ BC: breast cancer } \\
\hline
\end{tabular}

Table 2 - Patient and tumor characteristics.

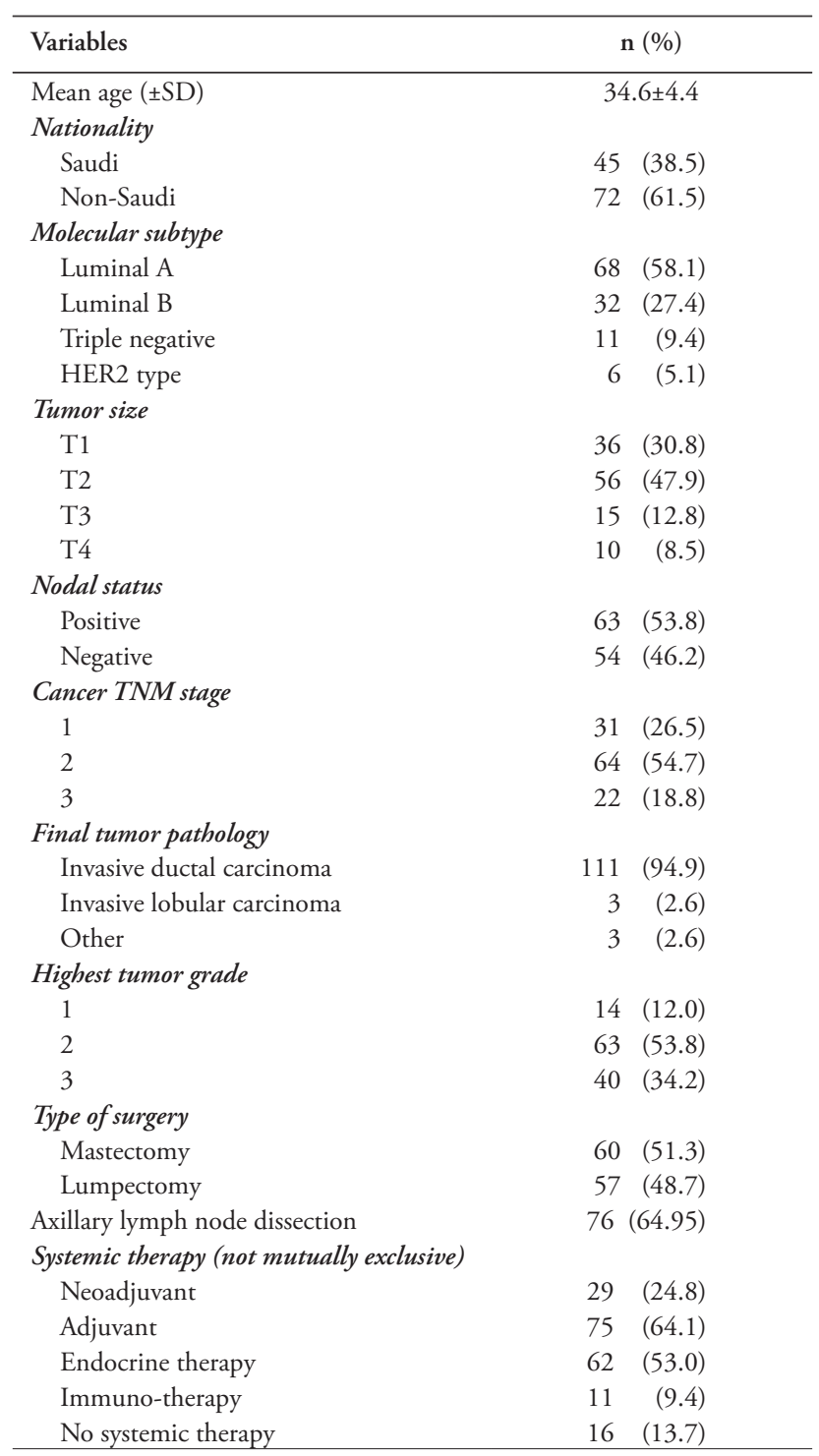

HER2: human epidermal growth factor receptor 2, TNM: tumor, node, metastasis, T: tumor 
followed by Trastuzumab in human epidermal growth factor receptor 2 positive patients; 5-FU, Doxorubicin, and Cyclophosphamide in $2(2.7 \%)$ patients; 5-FU, Epirubicin, and Cyclophosphamide (FEC100) in 3 (4.0\%) patients; and Docetaxel, Carboplatin, and Trastuzumab in $5(6.7 \%)$ patients. All the patients completed their treatment regimens as mentioned in the medical records, but no information on the adequacy of the regimen was recorded. Of those patients ( 42 patients) who did not undergo adjuvant treatment, $1(2.4 \%)$ had stage III disease, and $11(26.3 \%)$ had stage II disease. Thirty-nine (61.9\%) patients with stage II disease received adjuvant chemotherapy treatment, and $9(40.9 \%)$ patients with stage III disease received neoadjuvant chemotherapy treatment. During the follow-up period, 11 (9.4\%) patients had locoregional recurrence, while only $10(8.5 \%)$ had distant recurrence; there were only $6(5.1 \%)$ deaths according to the hospital death certificate data.

Chi-square analysis showed that nationality had no significant impact on recurrence, although non-Saudi patients tended toward a higher percentage of recurrence (22\%). Luminal-A molecular subtype, nodal status, TNM staging, type of surgery, and chemotherapy, did not show any statistically significant effect on recurrence rate. Overall survival was not analyzed, given the small number of deaths overall and in the different subgroups.

A Cox regression analysis was carried out to assess the impact of our variables on the participant's survival status. Univariate analysis showed that the use of adjuvant chemotherapy was associated with a better DFS (hazard ratio of $0.204 ; 95 \%$ confidence interval, 0.050 to 0.832 ; $p=0.027$ ). Diagnostic age, tumor size, nodal status, molecular subtype, and type of surgery showed no association with DFS or OS. (Table 3).

The Kaplan-Meier 5-year survival estimate for DFS was $57 \%$ and $89 \%$ for OS (Figures $1 \& 2$ ). The Kaplan-Meier estimates for DFS of patients was stage I was $54 \%$, stage II $54 \%$, and stage III was $42 \%$. Disease-free survival was significantly worse for patients with higher TNM stage $(p=0.034)$ (Figure 3). No significant difference was found in DFS with regards to the tumor size, ethnicity, and type of surgery on OS. There was no significant difference between the various groups, including nationality, type of surgery, and TNM stage. The non-parametric median test showed that fewer postoperative follow-up visits significantly predicted recurrence $(p=0.003)$ test showed that fewer postoperative follow-up visits significantly predicted recurrence $(p=0.003)$.

Discussion. Young-age BC (40 years of age and under) was more severe and has a poorer result

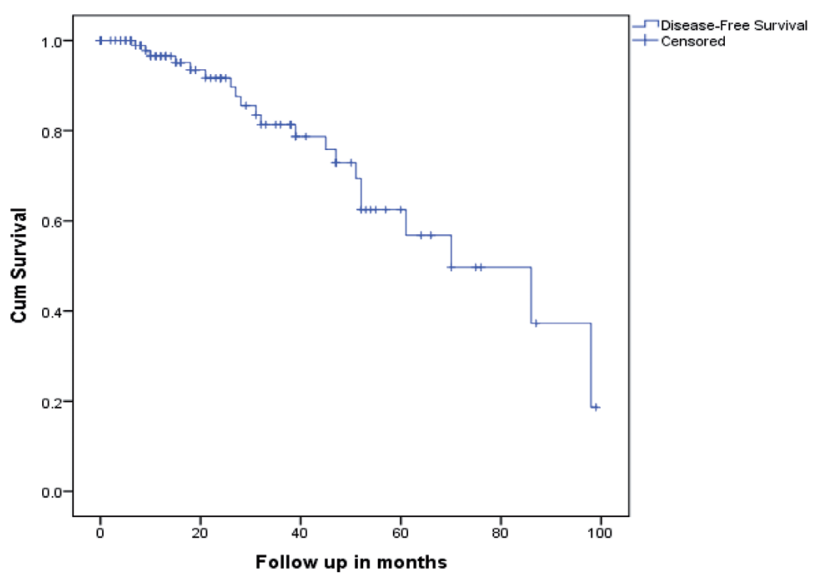

Figure 1 - Kaplan-Meier estimate for disease-free survival (recurrence).

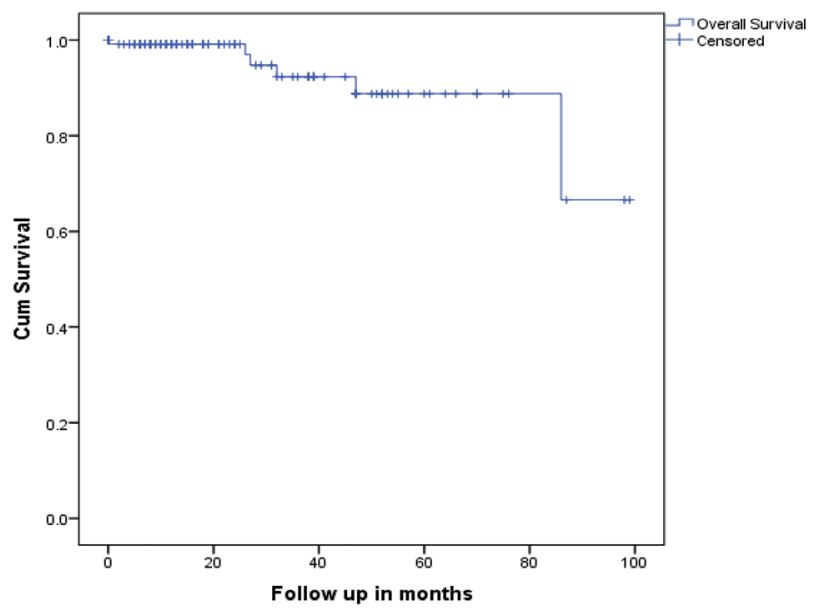

Figure 2 - Kaplan-Meier estimate for overall survival.

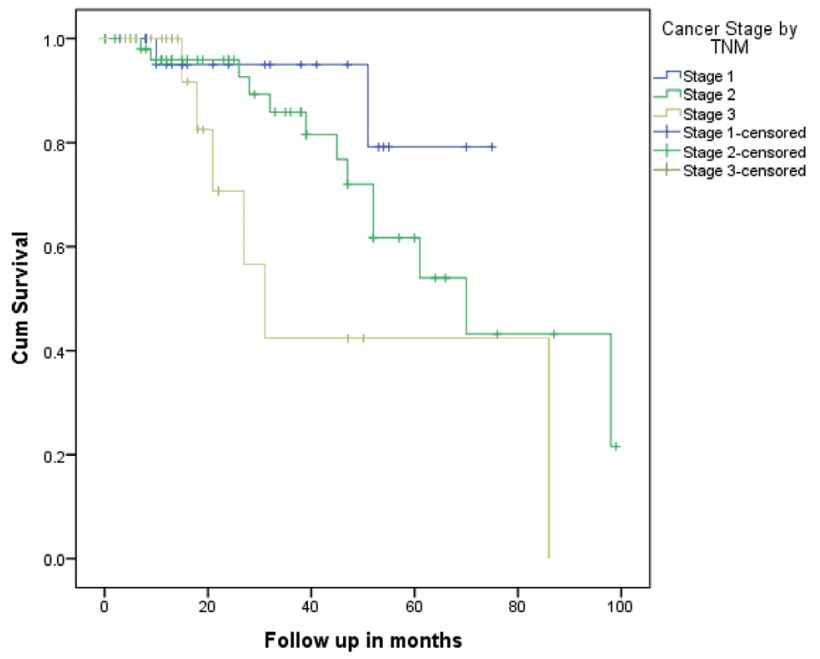

Figure 3 - Kaplan-Meier estimate stratified by tumor, node, metastasis of desease-free survival (recurrence) (log-rank test, $p=0.034)$. 
Table 3 - Univariate analysis (by Cox regression) of disease-free survival and overall survival.

\begin{tabular}{|c|c|c|c|}
\hline \multirow[t]{2}{*}{ Variables } & \multicolumn{3}{|c|}{ Univariate analysis } \\
\hline & Hazard ratio & $95 \% \mathrm{CI}$ & $P$-value \\
\hline \multicolumn{4}{|l|}{ Disease free survival } \\
\hline Age at diagnosis & 1.045 & $(0.913-1.196)$ & 0.525 \\
\hline Tumor size & 1.025 & $(0.852-1.233)$ & 0.792 \\
\hline Nodal status & 1.541 & $(0.465-5.104)$ & 0.479 \\
\hline \multicolumn{4}{|l|}{ Tumor grade } \\
\hline Grade 1 & Reference & & \\
\hline Grade 2 & 0.660 & $(0.079-5.530)$ & 0.702 \\
\hline Grade 3 & 0.291 & $(0.24-3.454)$ & 0.328 \\
\hline \multicolumn{4}{|l|}{ Molecular subtype } \\
\hline Luminal A & Reference & & \\
\hline Luminal B & 0.785 & $(0.161-3.834)$ & 0.765 \\
\hline Triple negative & 0.578 & $(0.066-4.565)$ & 0.578 \\
\hline HER2 type & 0.766 & $(0.084-6.169)$ & 0.766 \\
\hline Mastectomy & 0.495 & $(0.150-1.635)$ & 0.249 \\
\hline $\begin{array}{l}\text { Adjuvant } \\
\text { chemotherapy }\end{array}$ & 0.204 & $(0.050-0.832)$ & 0.027 \\
\hline \multicolumn{4}{|l|}{ Overall survival } \\
\hline Age at diagnosis & 0.836 & $(0.688-1.014)$ & 0.069 \\
\hline Tumor size & 1.117 & $(0.928-1.344)$ & 0.241 \\
\hline Nodal status & 0.281 & $(0.031-2.519)$ & 0.257 \\
\hline \multicolumn{4}{|l|}{ Tumor grade } \\
\hline Grade 1 & Reference & & \\
\hline Grade 2 & 0.777 & $(0.081-7.494)$ & 0.828 \\
\hline Grade 3 & 0.403 & $(0.025-6.445)$ & 0.520 \\
\hline \multicolumn{4}{|l|}{ Molecular subtype } \\
\hline Luminal A & Reference & & \\
\hline Luminal B & 0.000 & 0.000 & 0.978 \\
\hline Triple negative & 1.210 & $(0.134-10.938)$ & 0.865 \\
\hline HER2 type & 0.000 & 0.000 & 0.981 \\
\hline Mastectomy & 0.571 & $(0.104-3.147)$ & 0.571 \\
\hline $\begin{array}{l}\text { Adjuvant } \\
\text { chemotherapy }\end{array}$ & 1.007 & $(0.111-9.169)$ & 0.995 \\
\hline
\end{tabular}

than older age groups. ${ }^{22-25}$ Making it a study group of major importance. Thus, we looked at patient tumor characteristics in this study, aiming to find an understanding of which factors affect survival and recurrence rates.

We found a 5 -year rate of $89 \%$ OS and $57 \%$ rate of DFS. A study from the United States by Plichta et $\mathrm{al}^{20}$ reported that both 5-year OS and 5-year DFS to be $93 \%$. While Slaoui et $\mathrm{a}^{26}$ from Morocco, reported a 64.6\% 5-year DFS without addressing a figure for OS. Following-up on OS rates, we found that the study by Kallel et al, ${ }^{27}$ from southern Tunisia reported an OS of $75.2 \%$ in their institute. Narrowing down our field of view, we found studies to compare with across the Kingdom; the first of which is the study by Elkum et $\mathrm{al}^{28}$ conducted in the central part of Saudi Arabia, which reported a 5-year DFS of 77\%. While the study by Rudat et $\mathrm{al}^{29}$ conducted in the eastern part of Saudi Arabia, analyzed patients of all ages and reported a 2-year locoregional failure-free survival of $86 \%$. Both studies did not specify the younger age group in reporting survival and recurrence rates, but both concluded that young age was an independent $\mathrm{BC}$ recurrence risk factor. ${ }^{28,29}$ In contrast, we found a relatively low DFS, which could be due to lack of adherence to adjuvant treatment and postoperative follow-up, as we frequently encounter misconceptions related to adjuvant chemotherapy and radiotherapy. Furthermore, we found that fewer postoperative follow-up visits correlated with a higher risk of recurrence, thus negatively affecting DFS.

Additionally, despite patient beliefs on mastectomy as the better choice of treatment in preventing future recurrences versus lumpectomy, ${ }^{15,16}$ in our study, we did not detect a difference in OS or DFS when comparing lumpectomy and mastectomy outcomes. This finding is consistent with recent studies, most of which only mention the benefit of radiotherapy after lumpectomy procedures. ${ }^{30-33}$ The TNM stage in our sample was a significant predictor of DFS, and Wang et a ${ }^{34}$ reported an identical finding suggesting that higher the TNM stage, the worse the DFS. On the contrary, Plichta et $\mathrm{al}^{20}$ reported no association between DFS and TNM staging. One of the most important factors we investigated was the molecular subtype of the disease, which had no relation with survival in our population; these findings confirmed the conclusion of a study performed at the University of Tennessee, Knoxville, USA, which states that carcinoma subtype is not predictive of survival. ${ }^{35}$

Study limitations. Due to resource constraints, we included only a single center and focused on previously diagnosed cases; thus, the recruited sample was relatively small. Another limitation was the short follow-up time due to the lack of patient knowledge of its significance. Lastly, the scarcity of previous studies on the topic in our country. Nevertheless, in this study, we analyzed data from a tertiary care center and exclusively investigated a young age group with $\mathrm{BC}$, hoping that our study helps in setting screening guidelines suitable for the population in Saudi Arabia.

In conclusion, we found high risk of recurrence at our institution. Higher cancer stage, the nonuse of adjuvant chemotherapy, and low follow-up rate were significant predictive factors for recurrence. Furthermore, no postoperative difference in survival was found between mastectomy and lumpectomy.

Acknowledgment. We want to thank Editage (www.editage.com) for the English language editing. 


\section{References}

1. Noone AM HN, Krapcho M, Miller D, Brest A, Yu M, Ruhl J, Tatalovich Z, Mariotto A, Lewis DR, Chen HS, Feuer EJ, Cronin KAn editors. SEER Cancer Statistics Review, 1975-2015 SEER, National Cancer Institute: Bethesda, MD; 2018.

2. Ghoncheh M, Pournamdar Z, Salehiniya H. Incidence and mortality and epidemiology of breast cancer in the world. Asian Pac J Cancer Prev 2016; 17: 43-46.

3. El Bcheraoui C, Basulaiman M, Wilson S, Daoud F, Tuffaha M, AlMazroa MA, et al. Breast cancer screening in Saudi Arabia: free but almost no takers. PloS One 2015; 10: e0119051.

4. Assi HA, Khoury KE, Dbouk H, Khalil LE, Mouhieddine TH, El Saghir NS. Epidemiology and prognosis of breast cancer in young women. $J$ Thorac Dis 2013; 5 Suppl 1: S2-S8.

5. Fredholm H, Eaker S, Frisell J, Holmberg L, Fredriksson I, Lindman H. Breast cancer in young women: poor survival despite intensive treatment. PloS One 2009; 4: e7695.

6. Ribnikar D, Ribeiro JM, Pinto D, Sousa B, Pinto AC, Gomes E, et al. Breast cancer under age 40: a different approach. Curr Treat Options Oncol 2015; 16: 16.

7. Chollet-Hinton L, Anders CK, Tse CK, Bell MB, Yang YC, Carey LA, et al. Breast cancer biologic and etiologic heterogeneity by young age and menopausal status in the Carolina Breast Cancer Study: a case-control study. Breast Cancer Res 2016; 18: 79.

8. Ruddy KJ, Gelber S, Tamimi RM, Schapira L, Come SE, Meyer $\mathrm{ME}$, et al. Breast cancer presentation and diagnostic delays in young women. Cancer 2014; 120: 20-25.

9. Gogia A, Raina V, Deo SV, Shukla NK, Mohanti BK. Young breast cancer: A single center experience. Indian J Cancer 2014; 51: 604-608.

10. AlMadouj A, Alshahrani Z, Alrawaji A, Alzahrani W, Alomran F. Cancer Incidence Report 2015. In: Registry SC, editor. Riyadh, KSA: Saudi Health Council; September 2018. p. 60.

11. Liubota RV, Zotov AS, Vereshchako RI, Liubota, II, Zaychuk VV. Risk factors of the invasive breast cancer locoregional recurrence. Biomed Res Int 2015; 2015: 789646.

12. Favourable and unfavourable effects on long-term survival of radiotherapy for early breast cancer: an overview of the randomised trials. Early Breast Cancer Trialists' Collaborative Group. Lancet 2000; 355: 1757-17570.

13. Bartelink H, Horiot JC, Poortmans P, Struikmans H, Van den Bogaert W, Barillot I, et al. Recurrence rates after treatment of breast cancer with standard radiotherapy with or without additional radiation. $N$ Engl J Med 2001; 345: 1378-1387.

14. Cossetti RJ, Tyldesley SK, Speers CH, Zheng Y, Gelmon KA. Comparison of breast cancer recurrence and outcome patterns between patients treated from 1986 to 1992 and from 2004 to 2008. J Clin Oncol 2015; 33: 65-73.

15. Bijker N, Peterse JL, Duchateau L, Julien JP, Fentiman IS, Duval C, et al. Risk factors for recurrence and metastasis after breast-conserving therapy for ductal carcinoma-in-situ: analysis of European Organization for Research and Treatment of Cancer Trial 10853. J Clin Oncol 2001; 19: 2263-2271.

16. He XM, Zou DH. The association of young age with local recurrence in women with early-stage breast cancer after breastconserving therapy: a meta-analysis. Sci Rep 2017; 7: 11058.
17. Houssami N, Macaskill P, Marinovich ML, Morrow M. The association of surgical margins and local recurrence in women with early-stage invasive breast cancer treated with breastconserving therapy: a meta-analysis. Ann Surg Oncol 2014; 21 : 717-730.

18. Fisher CS, Martin-Dunlap T, Ruppel MB, Gao F, Atkins J, Margenthaler JA. Fear of recurrence and perceived survival benefit are primary motivators for choosing mastectomy over breast-conservation therapy regardless of age. Ann Surg Oncol 2012; 19: 3246-3250.

19. McGuire KP, Santillan AA, Kaur P, Meade T, Parbhoo J, Mathias M, et al. Are mastectomies on the rise? A 13-year trend analysis of the selection of mastectomy versus breast conservation therapy in 5865 patients. Ann Surg Oncol 2009; 16: 2682-2690.

20. Plichta JK, Rai U, Tang R, Coopey SB, Buckley JM, Gadd MA, et al. Factors Associated with Recurrence Rates and Long-Term Survival in Women Diagnosed with Breast Cancer Ages 40 and Younger. Ann Surg Oncol 2016; 23: 3212-3220.

21. Edge SB, Compton CC. The American Joint Committee on Cancer: the 7th edition of the AJCC cancer staging manual and the future of TNM. Ann Surg Oncol 2010; 17: 1471-1474.

22. Anders CK, Johnson R, Litton J, Phillips M, Bleyer A. Breast cancer before age 40 years. Semin Oncol 2009; 36: 237-249

23. Bharat A, Aft RL, Gao F, Margenthaler JA. Patient and tumor characteristics associated with increased mortality in young women ( $\leq 40$ years) with breast cancer. J Surg Oncol 2009; 100: 248-251.

24. Chen HL, Zhou MQ, Tian W, Meng KX, He HF. Effect of age on breast cancer patient prognoses: a population-based study using the SEER 18 database. PloS One 2016; 11: e0165409.

25. Martinez-Ramos D, Escrig J, Torrella A, Hoashi JS, Alcalde M, Salvador JL. Risk of recurrence of non-metastatic breast cancer in women under 40 years: a population-registry cancer study in a European country. Breast J 2012; 18: 118-123.

26. Slaoui M, Mouh FZ, Ghanname I, Razine R, El Mzibri M, Amrani M. Outcome of breast cancer in Moroccan young women correlated to clinic-pathological features, risk factors and treatment: a comparative study of 716 cases in a single institution. PloS One 2016; 11: e0164841.

27. Kallel M, Elloumi F, Khabir A, Ghorbal L, Chaabouni S, Amouri $\mathrm{H}$, et al. Breast cancer in young women in southern Tunisia: Anatomical study and clinical prognostic factors: About a series of 83 patients. Rep Pract Oncol Radiother 2015; 20:155-160.

28. Elkum N, Dermime S, Ajarim D, Al-Zahrani A, Alsayed A, Tulbah A, et al. Being 40 or younger is an independent risk factor for relapse in operable breast cancer patients: the Saudi Arabia experience. BMC Cancer 2007; 7: 222.

29. Rudat V, El-Sweilmeen H, Fadel E, Brune-Erber I, Ahmad Nour A, Bushnag Z, et al. Age of 40 years or younger is an independent risk factor for locoregional failure in early breast cancer: a single-institutional analysis in Aaudi Arabia. J Oncol 2012; 2012: 370385.

30. Kang I, Park S, Hur Ho, Park HS, Il Kim S, Cho SU. Oncologic safety of breast-conserving surgery in breast cancer patients under the age of 35. Korean J Clin Oncol 2017; 13: 32-38. 
31. Maishman T, Cutress RI, Hernandez A, Gerty S, Copson ER, Durcan L, et al. Local Recurrence and breast oncological surgery in young women with breast cancer: the POSH observational cohort study. Ann Surg 2017; 266: 165-172

32. Onitilo AA, Engel JM, Stankowski RV, Doi SA. Survival comparisons for breast conserving surgery and mastectomy revisited: community experience and the role of radiation therapy. Clin Med Res 2015; 13: 65-73.

33. Quan ML, Paszat LF, Fernandes KA, Sutradhar R, McCready DR, Rakovitch E, et al. The effect of surgery type on survival and recurrence in very young women with breast cancer. J Surg Oncol 2017; 115: 122-130.
34. Wang J, Li Q, Zhang P, Yuan P, Ma F, Luo Y, et al. TNM stage at diagnosis is more predictive of prognosis than pathological complete response in young breast cancer treated with neoadjuvant chemotherapy. Anti-Cancer Drug 2018; 29: 176-183.

35. Ferguson NL, Bell J, Heidel R, Lee S, Vanmeter S, Duncan $\mathrm{L}$, et al. Prognostic value of breast cancer subtypes, Ki-67 proliferation index, age, and pathologic tumor characteristics on breast cancer survival in Caucasian women. Breast J 2013; 19: $22-30$.

\section{Copyright}

Whenever a manuscript contains material (tables, figures, etc.) which is protected by copyright (previously published), it is the obligation of the author to obtain written permission from the holder of the copyright (usually the publisher) to reproduce the material in Saudi Medical Journal. This also applies if the material is the authors own work. Please submit copies of the material from the source in which it was first published. 